\title{
MRI CSF flowmetry in evaluation of different neurological diseases
}

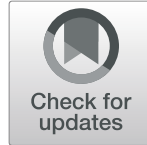

Nermin Ahmad', Dina Salama ${ }^{2}$ and Mohammad Al-Haggar ${ }^{2 *}$ (D)

\begin{abstract}
Background: Phase contrast MR imaging is a rapid and non-invasive technique which is sensitive in diagnosis and follow-up of different neurological diseases that cause CSF flow abnormality. MRI CSF flowmetry will be currently assessed in different neurological diseases that may cause CSF flow abnormalities.

Results: This study includes 39 patients with their ages ranging from 1 to 65 years; they were referred from the neurology department, with nine individuals of matched age and sex as a control group. Based on clinical history and conventional MRI, patients were subdivided into five subgroups; normal pressure hydrocephalus (NPH), hydrocephalus, idiopathic intracranial hypertension $(\mathrm{IIH})$, brain atrophy (BA), and Chiari malformation type I (CM-I). All patients and control were subjected to MRI CSF flowmetry evaluation with stress on peak diastolic velocity (PDV), peak systolic velocity (PSV), stroke volume (SV), and maximum velocity (Vmax). PDV, PSV, and SV were found significantly higher in NPH, CM-I, and hydrocephalus compared to control $(4.2,4.96$, and 83.23 for $\mathrm{NPH} ; 3.95,4.93$, and 37.38 for CM-1; and 4.2, 5.6, and 125 in hydrocephalus versus 2.11, 2.73, and 75.33 in control, respectively; $P=$ $0.0004,0.0008$, and 0.0009 for NPH; 0.03, 0.003, and 0.06 for $\mathrm{CM}-1$; and $0.0005,0.0002$, and 0.0003 , respectively). On the other hand, patients with BA showed significantly lower values $(1.37,1.66$, and 1.53 , respectively) compared to control ( $P=0.001,0.001$, and 0.004 , respectively).

Conclusion: MRI CSF flowmetry provides an easy, accurate, and non-invasive method for diagnosis of different neurological diseases that cause CSF flow abnormality. Moreover, this diagnostic modality could be helpful in selecting the therapeutic option.
\end{abstract}

Keywords: Phase contrast MRI, CSF

\section{Background}

Cerebrospinal fluid (CSF) is a clear, watery fluid that fills the ventricles of the brain and the subarachnoid space around the brain and spinal cord. CSF plays an important role in supporting the brain growth during evolution and protecting it against external trauma [1]. The normal CSF pressure is between 5 and $15 \mathrm{mmHg}(65-195$ $\mathrm{mm} \mathrm{H}_{2} \mathrm{O}$ ) in adults. In children younger than 6 years, normal CSF pressure ranges between 10 and $100 \mathrm{~mm}$ $\mathrm{H}_{2} \mathrm{O}$ [2]. CSF flows through the aqueduct of Sylvius and the foramen magnum is of a pulsatile "to and fro"

\footnotetext{
* Correspondence: m.alhaggar@yahoo.co.uk

2Department of Pediatrics, Faculty of Medicine, MUCH, Mansoura University, P.O. 35516 El-Gomhoria Street, Mansoura, Egypt

Full list of author information is available at the end of the article
}

nature. During systole, CSF flows through the aqueduct and foramen magnum in caudal direction which is reversed in diastole. It is this pulsatile flow which is detected and measured by phase-contrast MRI [3]. For CSF flow evaluation, two series of phase-contrast imaging techniques are applied. One in the axial plane with through-plane velocity encoding for flow quantification, and the other is in the sagittal plane, with in-plane velocity encoding for qualitative assessment. Throughplane evaluation is performed in axial oblique plane perpendicular to the long axis of the aqueduct, and it is more accurate for quantitative analysis because the partial volume effects are minimized [4].

Qualitative assessment is most beneficial in assessment of communication between the arachnoid cyst and 
subarachnoid CSF spaces. The plane of imaging is adjusted according to the expected point of communication; it may be in axial, sagittal, or coronal planes for detection pulsatile flow (black and white shades) at the neck of the cyst in phase images as evidence of communication with the subarachnoid spaces, as the pulsatile movement of the CSF in the subarachnoid spaces is transmitted to the neck of the cyst through the point of communication. Absence of such signal is an indicator of non-communication [5]. Finally, images obtained from phase-contrast (PC) MRI can be displayed in closed loop cine format or displayed as separate images. Post processing technique starts with manual drawing of a circular region of interest (ROI) on the phase images to include the whole pixels that represents the flow at the aqueduct. Direct measure of the velocity $(\mathrm{cm} / \mathrm{s})$ and volume flow rate $(\mathrm{ml} / \mathrm{min})$ of the moving spins can be extracted from velocitytime curves and flow-time curve $[6,7]$.

Phase-contrast MRI also can detect if there is communication with CSF or not in cases with arachnoid cysts which in turn provide the clinician with valuable data that allow him to choose the suitable method of treatment [5]. This imaging method can also help in determination of the severity of CSF flow abnormality that results from tonsillar herniation in Chiari 1 malformation. This may be guidance for the clinician to follow-up those patients after treatment $[8,9]$.

Normal pressure hydrocephalus (NPH) is a clinical syndrome characterized by gait disturbance, urinary incontinence, and dementia with normal CSF pressure. Hydrocephalus is a main finding in imaging. It is a rare disease but a treatable cause of dementia. Brain atrophy (BA) is a common feature of many diseases affecting the brain, which results in symptoms close to that of NPH; PC MRI is believed to be a reliable method in the diagnosis of NPH and differentiating it from brain atrophy [10].

Idiopathic intracranial hypertension (IIH) is a clinical syndrome characterized by raised intracranial pressure (ICP), in absence of a detectable cause and absence of hydrocephalus [11]. It leads to headache, papilledema, and visual disturbance that may ends with blindness in $10 \%$ of cases, without any lateralizing findings in the neurological examination, and normal CSF composition [12]. CSF flow by PC MRI in (IIH) patients, there was difference between the IIH groups and controls in mean rate and flow parameters; this difference suggests that CSF flow analysis by PC MRI may be a marker to follow-up IIH patients [13].

Chiari malformation type I (CM-I) is a condition characterized by downward displacement of the cerebellar tonsils through the foramen magnum and may be associated with or without syringomyelia. CSF flow studies using PC MRI are routinely used nowadays to determine the severity of CSF flow disturbance. The degree of CSF flow disturbance has been shown to correlate with severity and development of clinical symptoms [14].

Ventricular dilatation is the main finding in brain atrophy. It is always mild but symmetrical. Ventricular dilatation is proportional to the widening of the subarachnoid spaces; this change is better assessed on T1 WI MRI; abnormal high signal intensity white matter progressively increases with age as it results from ischemic changes. It may be seen in both deep and periventricular white matter [15]. CSF flow parameters are extracted in one cardiac cycle. Forward flow volume (ml) that represents the CSF flow volume in the encoding direction, while backward flow volume $(\mathrm{ml})$ represents CSF flow volume moving in the opposite direction. Regurgitation fraction ratio is the ratio of the smaller to the larger volume between the backward flow volume and the forward flow volume. The most important parameter calculated from these parameters is stroke volume $(\mathrm{ml})$ which is defined as the mean volume of CSF passing through the aqueduct in craniocaudal and caudocranial direction (Fig. 1) [16]. CSF flow velocity parameters quantify from velocity-time curve; in this curve, the area above the base line is the diastolic velocity, while the area below the base line is the systolic velocity. The curve is analyzed by the following parameters, peak diastolic velocity (PDV) $(\mathrm{cm} / \mathrm{sec})$, and peak systolic velocity (PSV) $(\mathrm{cm} / \mathrm{sec})$. Maximum CSF flow velocity (Vmax) in the aqueduct is calculated as the average of the absolute values of PDV and PSV (Fig. 2) [17].

For flow volume, maximum flow $\left(\mathrm{cm}^{3} / \mathrm{sec}\right)$ is calculated by multiplying ROI area $\left(\mathrm{cm}^{2}\right)$ with maximum velocity (Vmax) $(\mathrm{cm} / \mathrm{sec})$. Stroke volume represents the average of the volume flowing through aqueduct during systole and diastole, calculated by summation of forward flow volume and backward flow volume then multiply by two [6]. In the current work, MRI CSF flowmetry will be assessed in the different neurological diseases that may cause CSF flow abnormalities.

\section{Methods}

This prospective study was performed between July 2018 and December 2019. A total of 39 patients were enrolled in this study, 26 females and 13 males. Their mean age ranged from 1 to 65 years; they were referred from neurological departments of children and adults. The patients were divided into the following subgroups based on clinical and conventional MRI: NPH (12 patients), hydrocephalus group (11patients), IIH (7 patients), and brain atrophy (6 patients) while CM-I (3 patients) and control group (9) in number were free from any medical or neurological disease and had normal conventional MRI. 


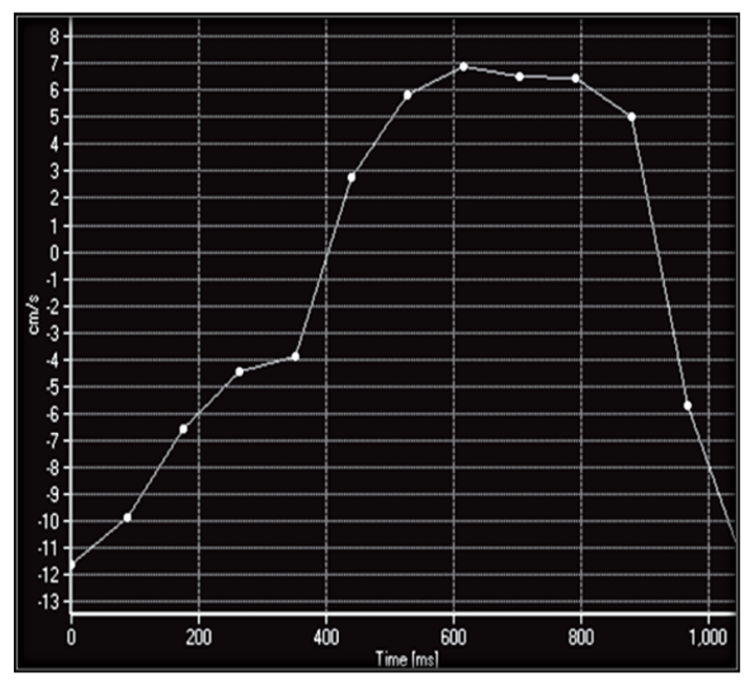

(A)

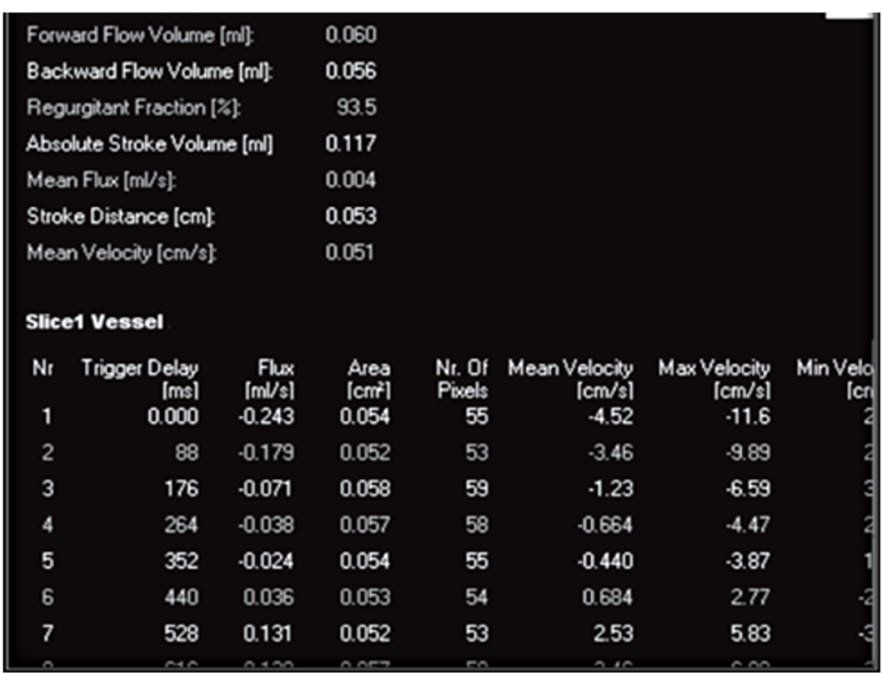

(B)

Fig. 1 a Maximum velocity-time graph following ROI placement on the cerebral aqueduct in phase-contrast images obtained [positive values (diastolic) show CSF flow velocity in the caudocranial direction and negative values (systolic) CSF flow velocity in the craniocaudal direction]. b CSF flow data [stroke volume $(\mathrm{ml})$, forward flow volume $(\mathrm{ml})$, backward flow volume $(\mathrm{ml})$, regurgitant fraction $(\%)$, absolute stroke volume $(\mathrm{ml})$, mean flux $(\mathrm{ml} / \mathrm{s})$, stroke distance $(\mathrm{cm})$, and mean velocity $(\mathrm{cm} / \mathrm{s})$ ] calculated for one cardiac beat by 2D-Q Flow software [16]

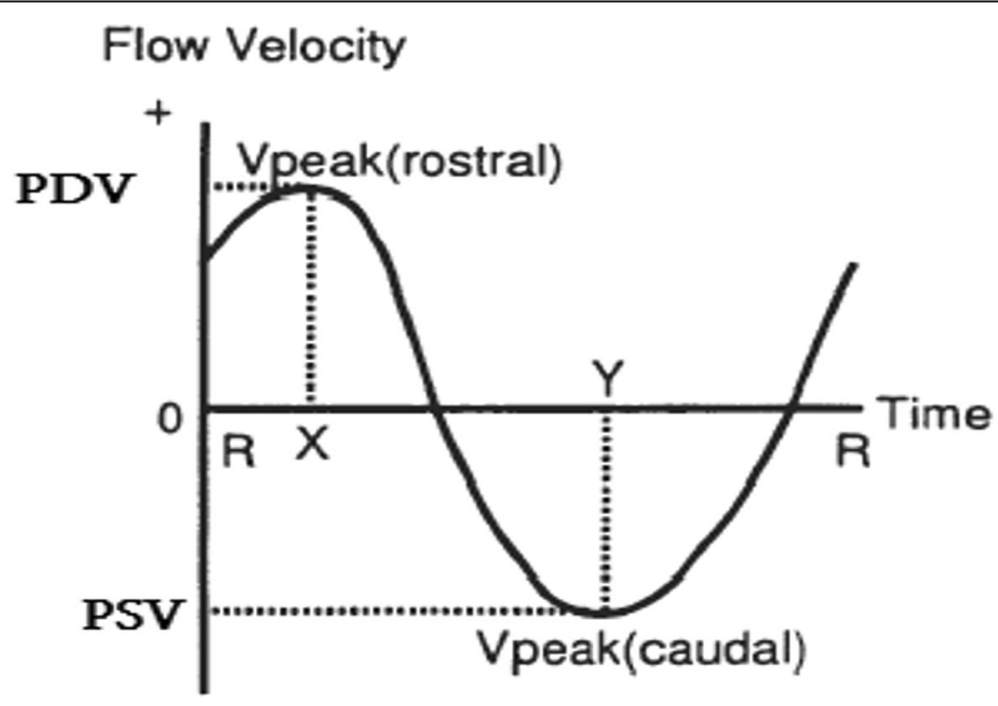

Fig. 2 Schematic drawing of CSF flow velocity show (PSV), (PDV), Vmax = (PSV + PDV)/2 [17] 
Table 1 Conventional MRI findings in each group

\begin{tabular}{ll}
\hline Group & MRI finding \\
\hline NPH group $(\boldsymbol{N}=\mathbf{1 2})$ & Evan index $>0.3(N=12)$ \\
Hydrocephalus group $(\boldsymbol{N}=\mathbf{1 1})$ & Aqueduct flow void sign $(N=5)$ \\
IIH group $(\boldsymbol{N}=\mathbf{7})$ & ventricular dilatation \\
& Empty sella $(N=4)$ \\
& Widened perioptic CSF space $(N=5)$ \\
BA group $(\boldsymbol{N}=\mathbf{6})$ & Posterior globe flattening $(N=2)$ \\
CM-I group $(\boldsymbol{N}=\mathbf{3})$ & Widened subarachnoid CSF space and cortical sulci $(N=5)$ \\
& White matter hyperintensities $(N=2)$ \\
& Herniation of the cerebellar tonsil beyond the foramen magnum \\
& Syringomyelia \\
& Aqueduct flow void sign
\end{tabular}

$\mathrm{NPH}$ normal pressure hydrocephalus, IIH idiopathic intracranial hypertension, $B A$ brain atrophy, $C M-I$ Chiari malformation type I

Table 2 Analysis of difference between normal pressure hydrocephalus (NPH) versus control group ( $t$ test)

\begin{tabular}{|c|c|c|c|}
\hline & $\mathrm{NPH}$ group, $N=12($ mean $\pm \mathrm{SD})$ & Control group, $N=9($ mean $\pm S D)$ & $P$ \\
\hline $\mathrm{PDV}(\mathrm{cm} / \mathrm{s})$ & $4.20 \pm 1.16$ & $2.11 \pm 0.37$ & $0.0004^{*}$ \\
\hline PSV $(\mathrm{cm} / \mathrm{s})$ & $4.96 \pm 1.55$ & $2.73 \pm 0.50$ & $0.0008^{*}$ \\
\hline $\operatorname{Vmax}(\mathrm{cm} / \mathrm{s})$ & $4.58 \pm 1.28$ & $2.42 \pm 0.26$ & $0.0005^{*}$ \\
\hline SV (ML) & $83.23 \pm 27.45$ & $25.33 \pm 5.30$ & $0.009^{*}$ \\
\hline Aqueduct area $\left(\mathrm{cm}^{2}\right)$ & $0.08 \pm 0.02$ & $0.04 \pm 0.01$ & $0.008^{*}$ \\
\hline Maximum flow $\left(\mathrm{cm}^{3} / \mathrm{s}\right)$ & $0.35 \pm 0.13$ & $0.12 \pm 0.04$ & $0.004^{*}$ \\
\hline
\end{tabular}

Data expressed as mean $\pm S D$. SD standard deviation, $P$ probability

*Significance $<0.05$

Table 3 Analysis of difference between Chiari malformation type I (CM-I) group versus control group ( $t$ test)

\begin{tabular}{llll}
\hline & CM-I group, $\boldsymbol{N}=\mathbf{3}($ mean \pm SD) & Control group, $\boldsymbol{N}=\mathbf{9}($ mean \pm SD) & $P$ \\
\hline PDV & $3.95 \pm 2.24$ & $2.11 \pm 0.37$ & $0.03^{*}$ \\
PSV & $4.93 \pm 1.67$ & $2.73 \pm 0.50$ & $0.003^{*}$ \\
SV & $37.38 \pm 16.21$ & $25.33 \pm 5.30$ & 0.06 \\
\hline
\end{tabular}

Data expressed as mean \pm SD. SD standard deviation, $P$ probability 
Table 4 CSF flow parameters in patient with hydrocephalus relative to control group

\begin{tabular}{llll}
\hline & Hydrocephalus, $\boldsymbol{N}=\mathbf{1 2}($ mean \pm SD) & Control group, $\boldsymbol{N}=\mathbf{9}($ mean \pm SD) & $P$ \\
\hline PDV & $4.2 \pm 0.22$ & $2.11 \pm 0.37$ & $0.0005^{*}$ \\
PSV & $5.6 \pm 0.65$ & $2.73 \pm 0.50$ & 0.0002 * \\
SV & $125 \pm 24$ & $25.33 \pm 5.30$ & 0.0003 *
\end{tabular}

Data expressed as mean \pm SD. SD standard deviation, $P$ probability

*Significance $<0.05$

Table 5 Analysis of difference between brain atrophy group versus control ( $t$ test)

\begin{tabular}{llll}
\hline & Brain atrophy, $\boldsymbol{N}=\mathbf{6}($ mean \pm SD) & Control group, $\boldsymbol{N}=\mathbf{9}(\mathbf{m e a n} \pm$ SD) & $P$ \\
\hline PDV $(\mathbf{c m} / \mathbf{s})$ & $1.33 \pm 0.44$ & $2.11 \pm 0.37$ & $0.001^{*}$ \\
PSV $(\mathbf{c m} / \mathbf{s})$ & $1.66 \pm 0.57$ & $2.73 \pm 0.50$ & $0.001^{*}$ \\
Vmax $(\mathbf{c m} / \mathbf{s})$ & $1.49 \pm 0.44$ & $2.42 \pm 0.26$ & $0.002^{*}$ \\
SV $(\mathbf{M L})$ & $11.63 \pm 4.31$ & $25.33 \pm 5.30$ & $0.004^{*}$ \\
Aqueduct area $\left(\mathbf{c m}^{2}\right)$ & $0.04 \pm 0.01$ & $0.04 \pm 0.015$ & 0.99 \\
Maximum flow $\left(\mathbf{c m}^{\mathbf{3}} / \mathbf{s}\right)$ & $0.07 \pm 0.02$ & $0.11 \pm 0.04$ & $0.017^{*}$
\end{tabular}

Data expressed as mean \pm SD. SD standard deviation, $P$ probability

*Significance $<0.05$
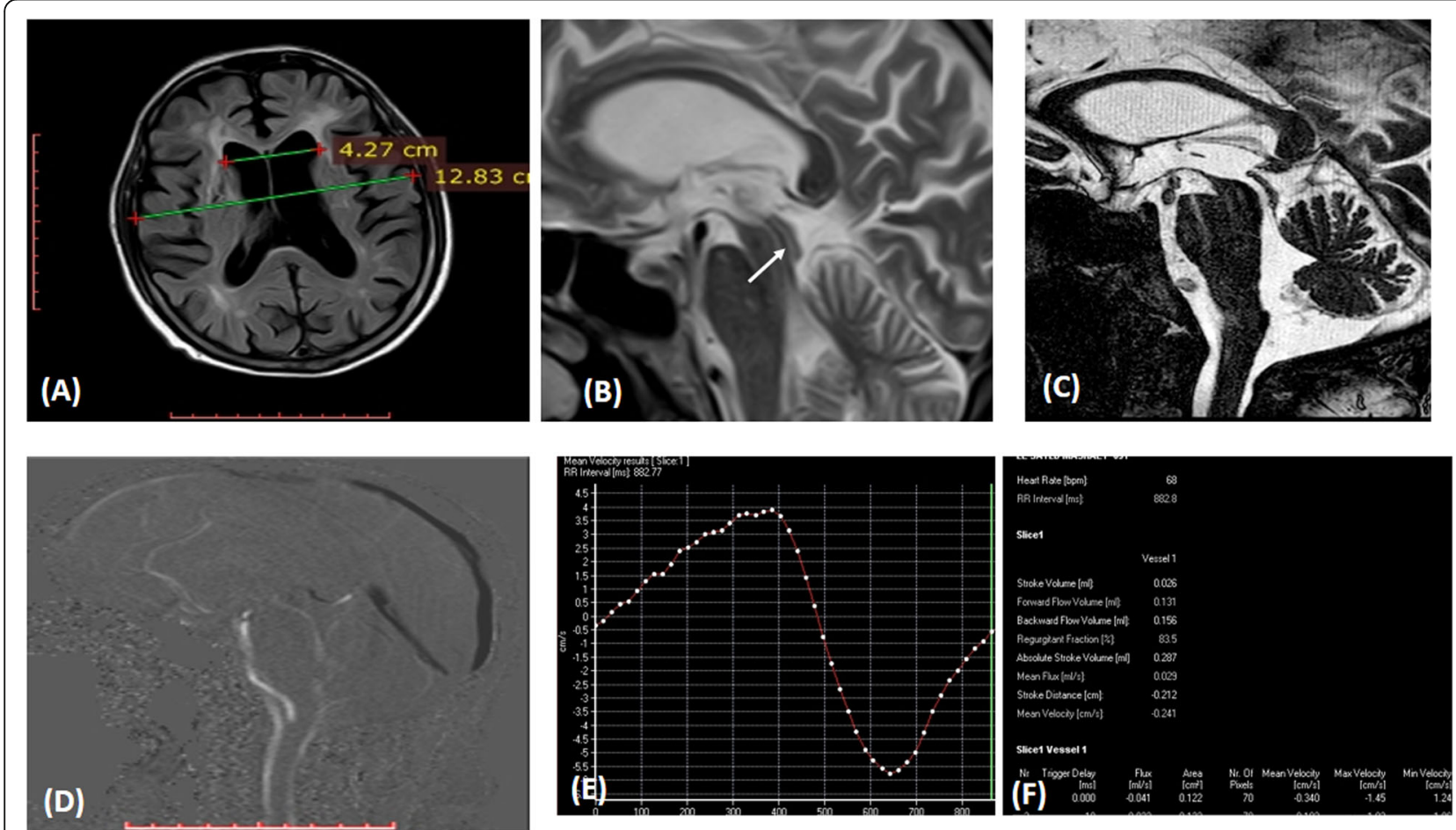

Fig. 3 Female patient aged 65 years old presented by memory disturbance, gait apraxia, and urinary incontinence. MRI (a) axial FLAIR at the level of the lateral ventricle showing hydrocephalus (Evan index $=0.33$ ). b Sagittal T2 WI showing the signal void sign at the aqueduct (white arrow). $\mathbf{c}$ 3D DRIVE image showing patent normal aqueduct. $\mathbf{d}$ CSF flow in the aqueduct of Sylvius as shades of white. Sagittal phase image in systole showing (e) velocity-time curve showing CSF in both diastole (above the base line) and systole (below the base line). PDV $=3.9 \mathrm{~cm} / \mathrm{s}$, PSV $=5.8$ $\mathrm{cm} / \mathrm{s}$. Vmax $=(3.9+5.8) / 2=4.85 \mathrm{~cm} / \mathrm{s}$. f CSF flow curve associated table demonstrating the following: forward flow volume $=131 \mu \mathrm{l}$, and backward flow volume $=156 \mu \mathrm{l}$, and so the $\mathrm{SV}=(131+156) / 2=143.5 \mu \mathrm{l} / \mathrm{cycle}$. Aqueduct area $=0.122 \mathrm{~cm}^{2}$. So the maximum flow was calculated as following: maximum flow $=4.85 \times 0.122=0.5917 \mathrm{~cm}^{3} / \mathrm{s}$. The diagnosis is hyperdynamic CSF circulation consistent with NPH 

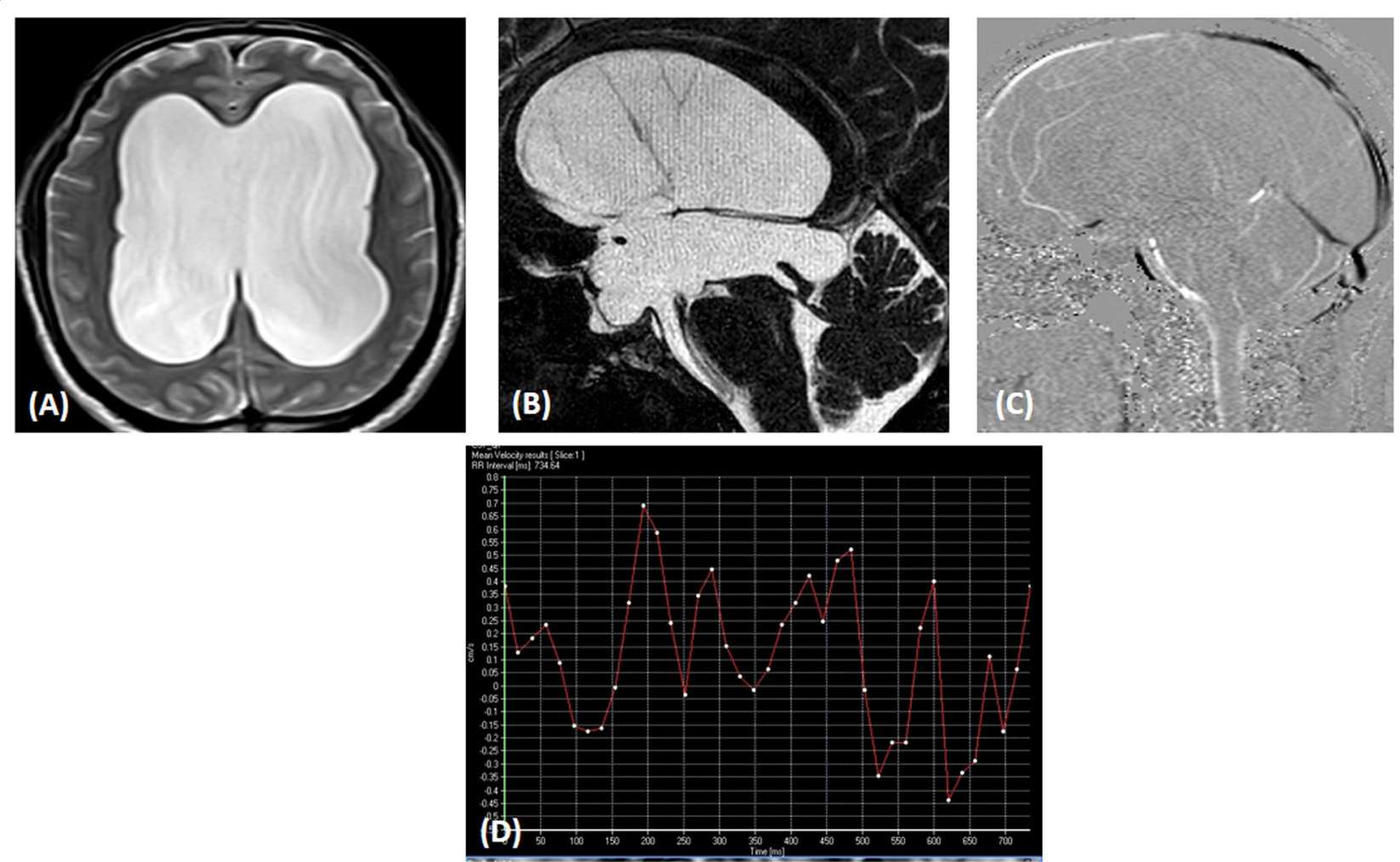

Fig. 4 Male patient aged 46 years old presented with headache axial T2 WI showing hydrocephalus. b 3D DRIVE image showing aqueductal web. c Sagittal phase image in systole showing no CSF flow in the aqueduct. $\mathbf{d}$ Velocity time curve showing markedly irregular CSF flow curve indicating irregular to and fro movement of the CSF proximal to the site of obstruction. Diagnosis is obstructive hydrocephalus caused by aqueductal web

\section{Phase contrast MRI protocol}

Sagittal 2D phase-contrast image were done for all patients using the following parameters: TR $21 \mathrm{~ms}$ TE ranged from 5.4 to $10 \mathrm{~ms}$, flip angle 10, matrix $256 \times 256$ pixels, slice thickness $=5 \mathrm{~mm}$. For axial phase-contrast image, the following parameters are used: TR ranged from 12 to $17 \mathrm{~ms}$, TE ranged from 7.3 to $10.4 \mathrm{~ms}$, flip angle $=15^{\circ}$, matrix $256 \times 256$ pixels, and slice thickness $=5 \mathrm{~mm}$. The first step was the cardiac gating. It was performed with MR compatible peripheral pulse transducer applied to the subject's finger.

In midsagittal image a localizer was placed perpendicular to the aqueduct of Sylvius, the localizer should pass through the aqueduct in the axial plane. Phase contrast images were obtained in one cardiac cycle. A series of phase and magnitude images at different cardiac phases were obtained.

After the data acquisition, all images were transferred to the workstation equipment with Q flow software. A region of interest was drawn manually to include all pixels that reflected the CSF flow signals on the phase images after magnification of the images to clarify the flow; after that, the CSF flow parameters were automatically extracted.

\section{Data analysis \\ Qualitative analysis}

Firstly, the images were analyzed in one setting for each case by the same radiologist, using midsagittal phase and magnitude images which revealed CSF flow in both systole and diastole; caudal flow in systole was represented as hyperintense signal, while the diastolic flow (cranial flow) was represented as hypointense signal, the change of flow in the aqueduct, during systole and diastole ruled out the presence of obstruction. Data were tabulated, coded, and then analyzed using the computer program SPSS (Statistical Package for Social Science) version 17.0.

\section{Descriptive data}

Descriptive data were expressed as follows: 

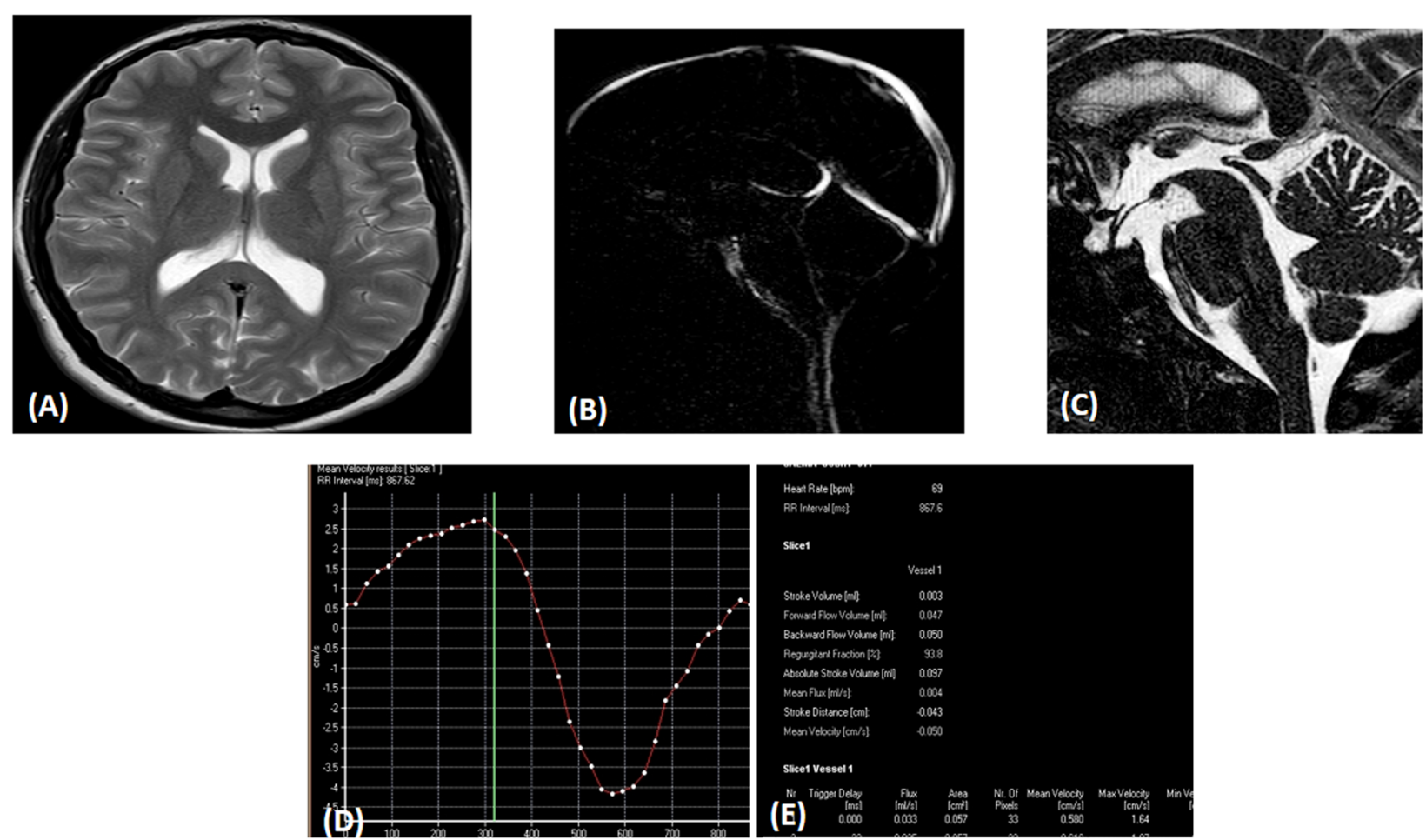

Fig. 5 Female patient aged 30 years old presented with visual impairment. MRI axial T2: Normal lateral ventricle. b 3D DRIVE image showing patent normal aqueduct. c Sagittal magnitude image showing CSF flow in the aqueduct of Sylvius as shades of white. d Velocity time curve showing CSF in both diastole (above the base line) and systole (below the base line). PDV $=2.6 \mathrm{~cm} / \mathrm{s}, \mathrm{PSV}=4.1 \mathrm{~cm} / \mathrm{s}, \mathrm{Vmax}=(2.6+4.1) / 2=3.35$ $\mathrm{cm} / \mathrm{s}$. e CSF flow curve. Forward flow volume $=47 \mu \mathrm{l}$ and backward flow volume $=50 \mu \mathrm{l}$, and so the $\mathrm{SV}=(47+50) / 2=48.5 \mu \mathrm{l} / \mathrm{cycle}$. Diagnosis is hyperdynamic CSF circulation consistent with IIH

1. Mean \pm standard deviation (SD) for parametric parameters

2. Median and range (minimum-maximum) for nonparametric parameters

3. Frequency (number-percent) for categorical parameters

\section{Analytical statistics}

Comparison between the different groups was done by the relevant test; significance of tests is considered if less than 0.05:

1. Student's $t$ test (unpaired). For comparison between means of two groups for parametric data

2. Mann-Whitney. For comparison between two groups as regards non-parametric variable

\section{Results}

This study included 39 cases, 26 females and 13 males. Their ages ranged from 1 to 65 years, all of them underwent conventional MRI (Table 1), and then PC MRI was done. For control, IIH, NPH, and BA groups, the parameters included SV, aqueduct area (ROI area, Fig. 1), PSV, PDV, and Vmax (Fig. 2) were extracted and calculated for each patient, maximum flow was calculated from the following equation: (maximum flow = Vmax $\times$ aqueduct area); their results were summarized (Tables 2, 3, 4, and 5).

PDV, PSV, and SV were found significantly higher in NPH (Table 2, Fig. 3), CM-I (Table 3), and hydrocephalus (Table 4, Fig. 4) compared to control (4.2, 4.96, and 83.23 for $\mathrm{NPH} ; 3.95,4.93$, and 37.38 for CM-I; 4.2, 5.6, and 125 in hydrocephalus versus 2.11, 2.73 , and 75.33 in control, respectively; $P=0.0004$, 0.0008 , and 0.0009 for NPH; $0.03,0.003$, and 0.06 for CM-I; and $0.0005,0.0002$, and 0.0003 , respectively). Similarly, IIH showed higher values compared to control $(\mathrm{PDV}=2.6, \mathrm{PSV}=4.1$, and $\mathrm{SV}=48.5$; Fig. 5). On the other hand, patients with BA showed significantly lower values $(1.37,1.66,1.53$, respectively) compared to control (Table $5, P=0.001,0.001$, and 0.004, respectively; Fig. 6). 

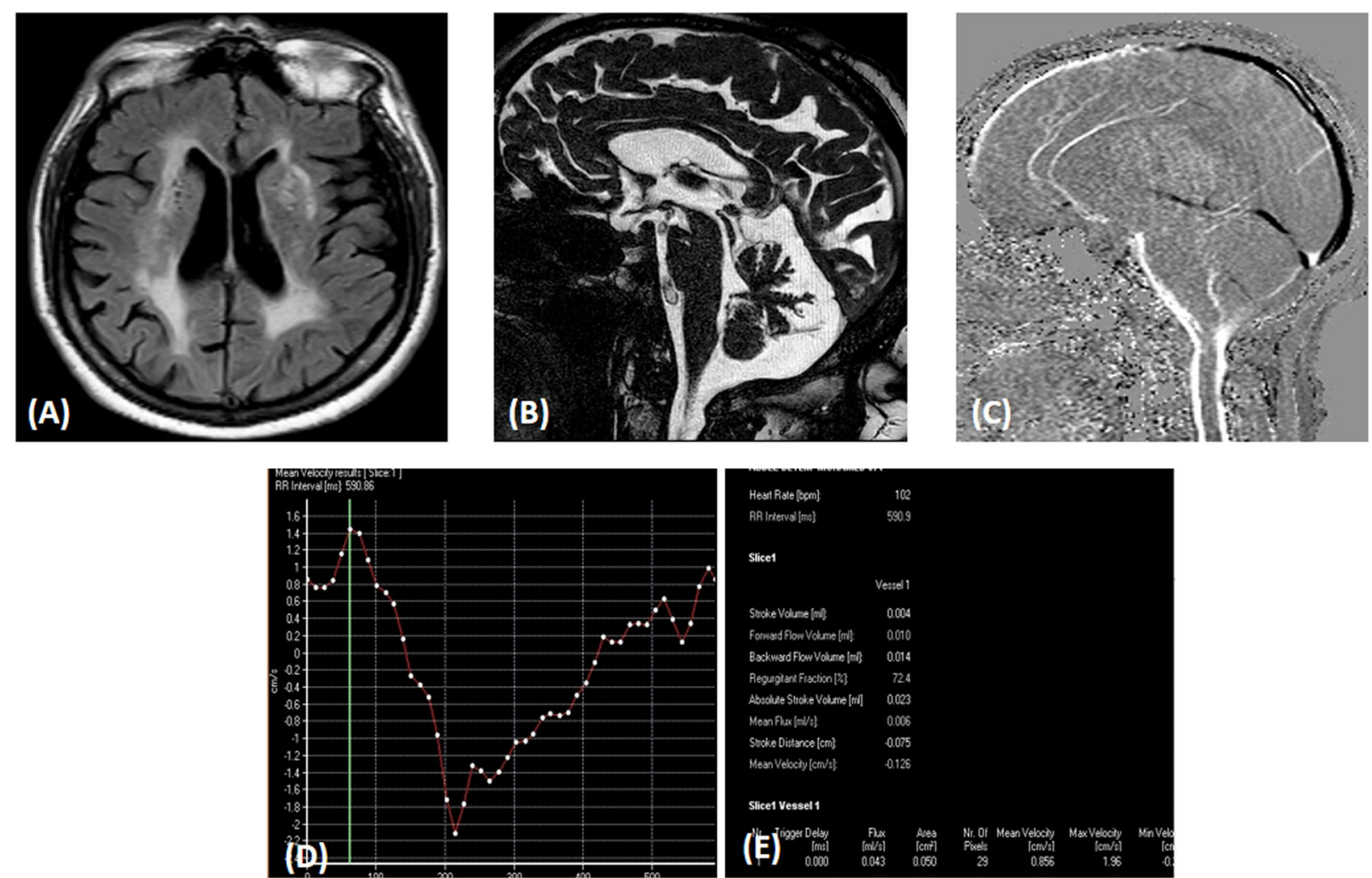

Fig. 6 Female patient presented with gait disturbance and difficult urinary control. a MRI axial FLAIR, mild dilatation of the lateral ventricles, and white matter abnormal hyperintensity representing ischemic changes. b 3D DRIVE image showing patent normal aqueduct. c Sagittal phase image in systole showing CSF flow in the aqueduct of Sylvius as shades of white. $\mathbf{d}$ Velocity time curve showing CSF in both diastole and systolic PDV $=1.4 \mathrm{~cm} / \mathrm{s}, \mathrm{PSV}=2.2 \mathrm{~cm} / \mathrm{s}$, and Vmax $=(1.4+2.2) / 2=1.8 \mathrm{~cm} / \mathrm{s}$. e CSF flow curve associated table, Forward flow volume $=10 \mu \mathrm{l}$, and backward flow volume $=14 \mu \mathrm{l}$, and so the $\mathrm{SV}=(10+14) / 2=12 \mu \mathrm{l} / \mathrm{cycle}$. Aqueduct area $=0.05 \mathrm{~cm}^{2}$. So the maximum flow was calculated as follows: maximum flow $=1.8 \times 0.05=0.09 \mathrm{~cm}^{3} / \mathrm{s}$. Diagnosis is hypodynamic CSF flow consistent with brain atrophy

\section{Discussion}

Many neurological diseases that results in changes in CSF dynamics include idiopathic intracranial hypertension (IIH), normal pressure hydrocephalus (NPH), brain atrophy (BA), Chiari malformation type I (CMI), and hydrocephalus. Phase contrast MRI CSF flowmetry can be used for qualitative and quantitative assessment of CSF flow abnormality in all the previously mentioned neurological condition [18]. Many parameters have been used for assessment of CSF flow by PC MRI including flow, and velocity parameter, stroke volume, peak systolic velocity, mean systolic velocity, forward flow volume, and backward flow volume [10].

In this study, six parameters were used to detect the CSF flow dynamics through aqueduct of Sylvius. Peak of the mean systolic and diastolic velocities is in centimeters/second; these parameters were extracted from mean velocity-time curve as the area above the baseline represents the CSF diastole, the area below the baseline represents the CSF systole. Maximum velocity
(Vmax) is in centimeters/second; it was calculated by absolute value of peak systolic and diastolic velocities divided by two. Aqueduct area was represented by the ROI area in square centimeters. Maximum flow is in square centimeters/second which was calculated by the following equation: maximum flow $=\operatorname{Vmax} \times$ ROI area. Stroke volume is the average of the CSF volume passing through aqueduct during systole and diastole in milliliters/cycle which was calculated from summation of forward flow volume and backward flow volume then divided all by two.

This study included 39 patients with different neurological diseases which were suspected to have CSF abnormality as follows: patients with NPH, IIH, BA, and hydrocephalus. Normal pressure hydrocephalus is one of the few treatable causes of dementia, but it is difficult to accurately differentiate it from BA. PC MRI provides a non-invasive tool for diagnosis of NPH and differentiates it from brain atrophy [10].

Phase contrast MRI was studied at the level of aqueduct in 12 patients with NPH; all parameters were found 
significantly higher in NPH group compared to the control group indicating hyperdynamic CSF flow in NPH patients. This was in agreement with Giner et al. who found that there was significant increase in PDV and SV in NPH patients compared with control group [19]. Hydrocephalus is classified into communicating and non-communicating (obstructive) and hence PC MRI can be used for such classification. Also, it can be used to determine the cause of obstruction in obstructive hydrocephalus if ordinary MRI sequences could not accurately detect it [20].

Eleven patients diagnosed to have obstructive hydrocephalus by conventional MRI were further investigated using PC MRI, which revealed the cause of hydrocephalus accurately; all of the patients were diagnosed as obstructive hydrocephalus by combination of conventional MRI, 3D DRIVE, and quantitative analysis through the aqueduct revealed irregular CSF flow curve, in agreement with Michali-Stolarska et al. who found that the curve to be irregular in cases of obstruction [20].

Idiopathic increased intracranial hypertension (IIH) is characterized by increased intracranial tension in absence of detectable cause. The diagnosis depends on clinical base (presence of papilledema on fundus examination and high CSF opening pressure done by lumber puncture) [21]. The same technique of PC MRI at the level of the aqueduct was applied on seven patients with $\mathrm{IIH}$; a statistically significant increase was observed in all parameters (apart from the aqueduct area).

Phase-contrast MRI in six patients with BA at the level of the aqueduct was interpreted using the same six parameters; a significant decrease in all parameters was observed in BA group compared to control indicating hypodynamic CSF flow.

Chiari malformation type I (CM-I) is abnormal downward descent of the cerebellar tonsil of at least $5 \mathrm{~mm}$ below the foramen magnum that causes increased resistance to CSF flow between the intracranial and spinal subarachnoid space. Detection of the severity of such CSF flow abnormality may help clinicians to choose patients who need surgical interference and to follow them postoperatively [22]. In our study, three patients with CM-I were diagnosed by PC MRI at two levels, at the aqueduct of Sylvius and at the craniocervical junction; there was a significant increase in PSV and PDV in CMI patients compared to control group $(P=0.03$ and 0.003 , respectively). However, the SV parameter showed insignificant difference.

Limitation of the current study was that all measurements had been done once without serial assessments of these parameters in subsequent follow-up evaluation.

\section{Conclusion}

MRI CSF flowmetry provides an easy and non-invasive method for diagnosis and follow-up of different neurological diseases that could cause CSF flow abnormality. Discrimination of NPH from brain atrophy can be achieved using MRI CSF flowmetry; however, it could be a useful tool for follow-up of IIH patients and for evaluation of the clinical course of CM-I prior and after surgery.

\section{Abbreviation}

PSV: Peak systolic velocity; PDV: Peak diastolic velocity; PC: Phase contrast; CSF: Cerebrospinal fluid; CM-I: Chiari malformation type I

\section{Acknowledgements}

We acknowledge our sincere thanks for all patients as well as our radiology staff members and technicians for their time and effort that they have spent throughout the work.

\section{Committee's reference number}

Not applicable.

\section{Authors' contributions}

All authors have read and approved the manuscript. NA undertakes the imaging procedure and interpretation of results and writes the manuscript. DS and MA recruited the pediatrics cases from neurologic clinics and reviewed and revised the manuscript.

\section{Funding}

Not applicable.

\section{Availability of data and materials}

The datasets used and/or analyzed during the current study are available from the author (NA) on reasonable request.

\section{Ethics approval and consent to participate}

This work had followed the ethical committee guidelines of IRB in our institute, Mansoura University Children's Hospital (MUCH). Written informed consent had been taken from all patients or their guardians, if they are younger than 16-year-old before carrying out the study.

\section{Consent for publication}

All patients included in this study gave written informed consent to publish the data contained within this study. If patients were less than 16-year-old, deceased, or unconscious when the consent for publication was requested, written informed consent for the publication of this data was given by their parents or legal guardians.

\section{Competing interests}

The authors declare no competing interests.

\section{Author details}

'Department of Radiology, Mansoura University Children's Hospital (MUCH), Mansoura, Egypt. ${ }^{2}$ Department of Pediatrics, Faculty of Medicine, MUCH, Mansoura University, P.O. 35516 El-Gomhoria Street, Mansoura, Egypt.

Received: 2 December 2020 Accepted: 30 January 2021

Published online: 12 February 2021

\section{References}

1. Fan H, Giiang L, Huang T, Juan C, Chen C, Chen S (2012) 337 cerebrospinal fluid flow quantification of the cerebral aqueduct in children and adults with two-dimentional cine phase-contrast cine MR imaging. Arch Dis Child 97:A99-A

2. Suman A, Pandya S (2018) Gross anatomy of cerebral ventricles and septum pellucidum of brain of Surti Buffalo (Bubalus bubalis). Indian J Vet Sci Biotech 14:14-17

3. Raybaud C (2004) Radiological assessment of hydrocephalus: new theories and implications for therapy. Neurosurg Rev 27:167 
4. Puy V, Zmudka-Attier J, Capel C, Bouzerar R, Serot J-M, Bourgeois A-M, Ausseil J, Balédent O (2016) Interactions between flow oscillations and biochemical parameters in the cerebrospinal fluid. Front Aging Neurosci 8 : 154

5. Yildiz H, Erdogan C, Yalcin R, Yazici Z, Hakyemez B, Parlak M, Tuncel E (2005) Evaluation of communication between intracranial arachnoid cysts and cisterns with phase-contrast cine MR imaging. A J Neuroradiol 26:145-151

6. Unal O, Kartum A, Avcu S, Etlik O, Arslan H, Bora A (2009) Cine phasecontrast MRI evaluation of normal aqueductal CSF flow according to sex and age. Diagn Interv Radiol 15:227-231

7. Korosec FR (2012) Basic principles of MRI and MR angiography. In: James C, Timothy J (eds) Magnetic resonance angiography. Springer Science, Business Media, pp 3-38

8. Haughton VM, Korosec FR, Medow JE, Dolar MT, Iskandar BJ (2003) Peak systolic and diastolic CSF velocity in the foramen magnum in adult patients with Chiari I malformations and in normal control participants. AJNR Am J Neuroradiol 24:169-176

9. Bapuraj JR, Londy FJ, Delavari N, Maher CO, Garton HJ, Martin BA, Muraszko KM, Ibrahim ESH, Quint DJ (2016) Cerebrospinal fluid velocity amplitudes within the cerebral aqueduct in healthy children and patients with Chiari I malformation. J Magn Reson Imaging 44:463-470

10. Senger KPS, Singh RK, Singh AK, Singh A, Dashottar S, Sharma V, Mishra A (2017) CSF flowmetry: an innovative technique in diagnosing normal pressure hydrocephalus. Int J Adv Med 4:682-687

11. Ball AK, Clarke CE (2006) Idiopathic intracranial hypertension. Lancet Neurol 5:433-442

12. Wakerley B, Tan M, Ting E (2015) Idiopathic intracranial hypertension. Cephalalgia 35:248-261

13. Akay R, Kamisli O, Kahraman A, Oner S, Tecellioglu M (2015) Evaluation of aqueductal CSF flow dynamics with phase contrast cine MR imaging in idiopathic intracranial hypertension patients: preliminary results. Eur Rev Med Pharmacol Sci 19:3475-3479

14. Fakhri A, Shah MN, Goyal MS (2015) Advanced imaging of Chiari 1 malformations. Neurosurg Clin N Am 26:519-526

15. Barkhof F, Fox NC, António J, Bastos-Leite, Scheltens P (2011) Normal aging. In: Neuroimaging in dementia. Springer Science \& Business Media, Verlag Berlin Heidelberg, pp 43-57

16. Gorucu Y, Albayram S, Balci B, Hasiloglu ZI, Yenigul K, Yargic F, Keser Z, Kantarci F, Kiris A (2011) Cerebrospinal fluid flow dynamics in patients with multiple sclerosis: a phase contrast magnetic resonance study. Funct Neurol 26:215-222

17. Kim DS, Choi J-U, Huh R, Yun P-H, Kim D-I (1999) Quantitative assessment of cerebrospinal fluid hydrodynamics using a phase-contrast cine MR image in hydrocephalus. Childs Nerv Syst 15:461-467

18. Battal B, Kocaoglu M, Bulakbasi N, Husmen G, Tuba Sanal H, Tayfun C (2011) Cerebrospinal fluid flow imaging by using phase-contrast MR technique. $\mathrm{Br}$ J Radiol 84:758-765

19. Giner JF, Sanz-Requena R, Flórez N, Alberich-Bayarri A, García-Martí G, Ponz A, Martí-Bonmatí L (2014) Quantitative phase-contrast MRI study of cerebrospinal fluid flow: a method for identifying patients with normalpressure hydrocephalus. Neurología (English Edition) 1 29(2):68-75

20. Michali-Stolarska M, Bladowska J, Stolarski M, Sąsiadek MJ (2018) Diagnostic imaging and clinical features of intracranial hypotension: review of literature. Pol J Radiol 83:e11-e18

21. Friedman DI, Liu GT, Digre KB (2013) Revised diagnostic criteria for the pseudotumor cerebri syndrome in adults and children. Neurology 81:11591165

22. Dlouhy BJ, Dawson JD, Menezes AH (2017) Intradural pathology and pathophysiology associated with Chiari I malformation in children and adults with and without syringomyelia. J Neurosurg Pediatr 20:526-541

\section{Publisher's Note}

Springer Nature remains neutral with regard to jurisdictional claims in published maps and institutional affiliations.

\section{Submit your manuscript to a SpringerOpen ${ }^{\circ}$ journal and benefit from:}

- Convenient online submission

- Rigorous peer review

- Open access: articles freely available online

- High visibility within the field

- Retaining the copyright to your article

Submit your next manuscript at $\boldsymbol{\nabla}$ springeropen.com 